\title{
Discussion on Elevation Policy of Graduate Courses Teaching Quality
}

\author{
Muwei Zhang \\ Jilin Agricultural University College of Humanities, China \\ zmw0302129@163.com
}

\begin{abstract}
Graduate teaching quality is the key to affect the quality of postgraduate training; it is a good basis for the completion of graduate dissertations. This article aims to analyze the impact factors of the quality of teaching graduate courses, the corresponding system reform strategy in curriculum development, curriculum teaching methods, curriculum assessment methods, and supervision and evaluation mechanism curriculum, teaching management, etc., in order to enhance the quality of teaching graduate courses.
\end{abstract}

Keywords: postgraduate; course; quality; upgrade.

\section{Introduction}

"Higher Education Act" expressly provides that graduate education should enable students to master firm basic theory and professional knowledge systems to master the skills, techniques and related knowledge, the ability for the practical work and research in the [1]. Graduate Courses Graduate Education is basic link, determines the quality and level of graduate education, affect the innovative ability of postgraduates[2]. Course teaching lay a solid theoretical foundation for graduate students to carry out research work, it plays a decisive role in postgraduate education and training process.

\section{The influencing factors on the quality of the graduate student curriculum teaching analysis}

(1) The curriculum system settings. Academic Master now according to the level of student recruitment and training, press the past two subjects different culture, some disciplines training scheme is not scientific and reasonable according to the requirement of the level 1 discipline integrating graduate course system; because the university full-time students pursuing degree late start, the course is still in the system settings continue to accumulate experience and improve the stage, theory and Practice Course set not fully suitable for professional postgraduate training objectives.

(2) The course teaching methods. Traditional "indoctrination" teaching model leads to a lack of students' ability to think independently. There are many classroom teachers are not effectively organized, effective questions, guide, special classes, class discussion a "mouthpiece", the lack of graduate students theoretical knowledge applied to solve practical problems training. This kind of "reception-style" approach to learning, is not conducive to the students to develop the habit of active thinking, so that students ideological rigidity and lack of academic challenge the authority of the spirit, is not conducive to the cultivation of postgraduates' innovation ability.

(3) The course assessment methods. Postgraduate Curriculum Evaluation Mode mainly in the form of a closed book exam or written coursework for examination. Long-term exam-oriented education makes the poor students found new problems independently. Some of Postgraduate downloads information from the Internet, to cope with a course paper. Although students with higher grades passed the exam, but there is no comprehensive thorough understanding of the course content and its theoretical basis is low, the scientific research innovation lagged.

(4) Monitoring evaluation mechanism of the courses. At present, the main targets for the teacher is to undertake major research projects and funding situation, published papers, was less about teaching is mentioned, the evaluation of teaching has become the "soft targets." At present, teachers of postgraduate students scientific research task is heavier, even some teachers also perform administrative duties, affecting the orderly conduct of the course teaching. Sound postgraduate supervision evaluation mechanism can effectively protect the order and the quality of teaching. 
(5) Graduate teaching management. Graduate teaching and training process management, we must first rely on a sound regulatory framework. With the rapid increase of graduate education scale, the graduate education in universities is generally adopting the secondary management mode. The quality of graduate teaching management team to some extent determines the Graduate Courses can be ordered. Set up an authority and clear teaching management team is very important. Working with the school authorities and Graduate School of Management Graduate teaching staff between teaching graduate courses are also important factors affecting the quality.

\section{The main strategy to enhance the quality of teaching graduate course}

(1) Build a scientific and rational curriculum. Each professional academic curriculum system set up to cover the disciplines basic theory, systematic professional knowledge and reflect academic frontiers of new knowledge, new technology, and connecting with the school discipline characteristic curriculum. Teaching content can highlight the frontier and relates to high or low innovative ability of graduate students scientific research and the size of the innovation [3]. In the curriculum, courses can be set up two subjects, two subjects itself to reflect the characteristics of structure and discipline necessary knowledge; professional foundation courses should be set according to a discipline, reinforce discipline basics. In order to ensure effective convergence course content, avoid overlapping course content, should be within the discipline of teaching content of courses by full discussion, form a scientific and standardized course syllabus. During the development of the syllabus, the syllabus can continue to be revised and improved, will continue to subject content and the latest cutting-edge technology, the introduction of advanced research methods teaching to make students based on the development and evolution of knowledge through systematic study and master course wide profound theoretical knowledge. Postgraduate Degree in various fields to develop training programs should be fully reflected in the training objectives, on the curriculum should pay attention to practical application ability and innovation ability of the knowledge system construction, reasonable arrangement of theory and practice of teaching content.

(2) Establish discussion interactive teaching mode. The creation of democracy and freedom in teaching graduate course in the academic atmosphere, teaching and research can be used to impart teaching a combination of teaching methods, and focus on the discussion teaching methods; academic frontier seminars and literature review classes can be used for discussion type teaching method, through academic reports and academic exchanges, to make students more extensively involved broaden academic horizons discussion [4]. Teachers must guide students in the form of research studies to learn to identify problems, analyze and solve problems, to stimulate their intellectual curiosity and desire to explore desire. Encourage between graduate students, graduate students and teachers to the benign interaction, emphasis on "not angry not rev, unable to express or explain oneself not hair", and so truly, cultivate and improve the graduate student's innovation ability and scientific research ability.

(3) Reform Curriculum Evaluation Mode. Postgraduate course grade examinations should be diversified, results diversified composition, examinations should break the scope of teaching, both knowledge and ability assessment. Specifically from classroom attendance, lectures, class discussions, homework, conduct experiments and design, reading literature, completed coursework, course examinations and other aspects of a comprehensive assessment. To strengthen the graduate learning process assessment, to increase the proportion of normal results, so that students usually pay attention to the accumulation of knowledge, solid, systematic mastery of curriculum theory; change the way the past memory type assessment, through the panel discussion, experimental design, course work, testing students using knowledge analysis solution actual problem ability; students are encouraged to read a lot of literature to learn cutting-edge knowledge and discipline development, engaged in scientific research to solve practical problems and lay a solid theoretical foundation.

(4) Build up reasonable curriculum evaluation assessment mechanism. The teachers to participate in teaching research, teaching reform, the teaching effect in the teacher evaluation system, the 
evaluation results with the enrollment qualifications, the teaching level of qualifications, job, title evaluation, such as hooks, to establish reasonable structure of the graduate students to develop the teachers troop. Establish teaching evaluation mechanism to understand the needs of graduate course content and teaching methods the course satisfaction, and promote teachers to improve classroom teaching. The course evaluation mechanism should also include teacher assessment science section, which is, from teachers to students' learning attitude, learning situation, learning evaluation. Teachers will graduate student attendance, class participation as an evaluation of the effect of postgraduate study an important indicator of discussions, job completion, formed from the school, to work, to the examination of the "teach one or two to learn, test three" positive "pyramid" structure [5].

(5) Strengthen the construction of teaching administration. Establish and improve the graduate students' management system, is the guarantee of normal orderly teaching each link. Colleges and universities to establish a strong sense of responsibility and mission management team of high-quality postgraduate teaching, correctly grasp the national education policies. Establish a people-oriented management philosophy, graduate students willing to learn, hard, from passive learning to active learning good style of study. Second-tier management should ensure relatively stable teaching secretaries, to make the transition when replacing old and new newcomers. Regularly teaching management training, promote college Management staff work closely with each other to ensure the teaching work carried out smoothly. Teaching management staff to make full use of modern management tools to continuously improve work efficiency, advancing learning and knowledge management business knowledge, enhance the theoretical level and practical ability, to enhance the quality of teaching graduate course provide a stable rear-area support.

\section{Conclusion}

Education is the foundation. Graduate education is the highest level of education in our country, assuming the historical mission of training high-level talents directly. Quality education and training of graduate students decided to "education" effective implementation of the strategy. Postgraduate enrollment has grown, how to improve the quality of teaching graduate courses become an important topic in Universities. Postgraduate Course is to train graduate students' creative ability and basic research capabilities, teaching reform and improve the quality of teaching graduate courses on training high-level, innovative graduate has far-reaching significance. Graduate teaching process must strengthen the monitoring program, to develop a reasonable and effective rules and regulations to carry out the implementation, in order to ensure and enhance the quality of postgraduate education and foster high quality, high levels of complex research talent.

\section{References}

[1] Falan Qin, Hua Wang, Chengxiao Hu. The main problems and countermeasures study in Graduate course teaching [J].

[2] Dihong Bao, Xuemei Jiang, Yong Huang. Thoughts on Improving Teaching and Research Postgraduates in China [J]. Heilongjiang province higher education research, 2015 (6).

[3] Changxin Li. Graduate student curriculum teaching research and its improved strategy [J]. China Higher Education Research, 2012 (4).

[4] yajun Di, Minghu Ha. Graduate courses of teaching problems and countermeasures [J]. China Higher Education Research, 2014, (6).

[5] Juan $\mathrm{Xu}$, Chuanwei Li. North American College graduates curriculum impression [J]. Chinese graduate student, 2015 (6). 